\title{
Retrospectiva internacional 2020
}

\section{International 2020 retrospective} Por Ana Prestes*

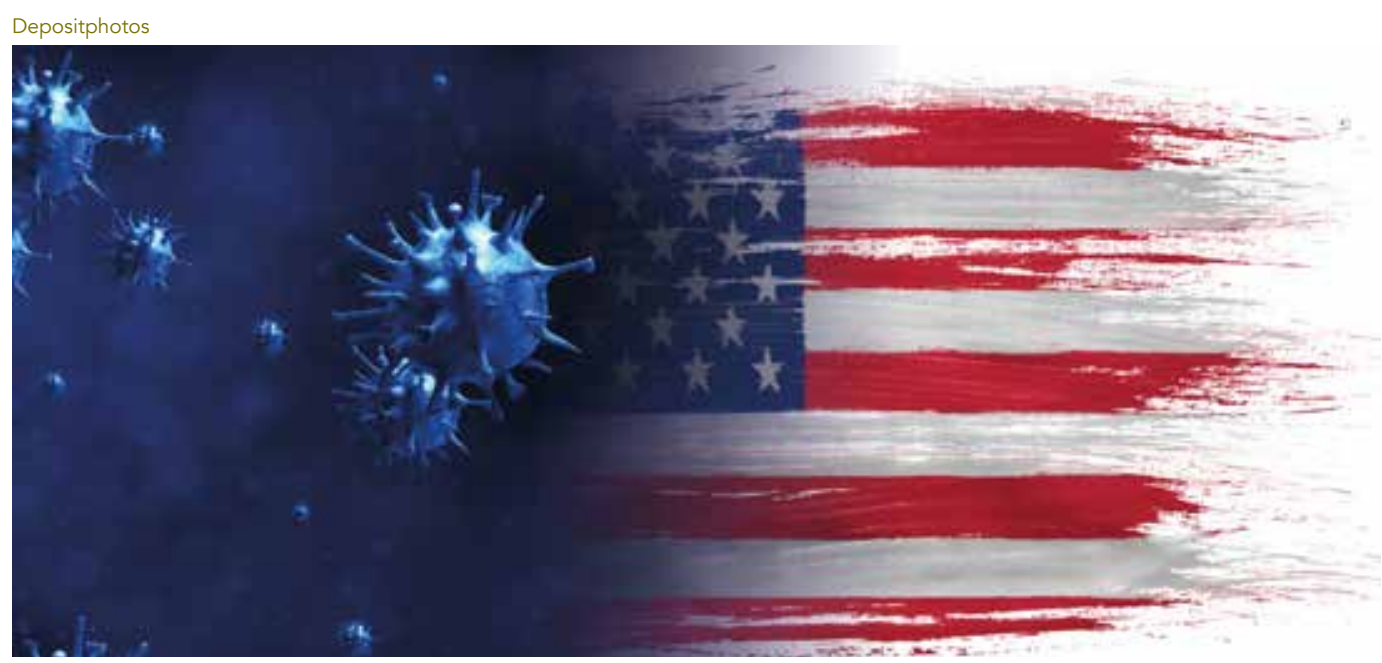

\section{Pandemia}

O ano de 2020 foi de pandemia global. Causada por um novo patógeno da família do coronavírus, a crise sanitária atingiu, em números oficiais, 80 milhões de pessoas em todo o mundo, ceifando quase 2 milhões de vidas. O surto de covid-r9 - doença até então desconhecida - começou em dezembro de 2019 na China. Em janeiro, a OMS deu o primeiro alerta mundial sobre a circulação de um novo vírus que estava matando pessoas em Wuhan, na província de Hubei. Seu espalhamento começou pela Ásia, depois chegou a Oceania, Europa, Américas e, por fim, à África. Em março, a OMS decretou que o mundo estava enfrentando uma pandemia. O fenômeno desencadeou uma crise mundial de várias faces, sanitária, econômica, política e social. Cada país lidou com o fenômeno à sua maneira, havendo desde os que adotaram as mais profundas medidas restritivas, como China e Nova Zelândia, até os mais liberais, como Reino Unido e Suécia. Houve também os inconsequentes, como EUA e Brasil. Os números não mentem sobre quais países tiveram as medidas mais eficazes. Os EUA terminam 2020 com mais de 300 mil mortes e a China com 5 mil. Houve aqueles que usaram a pandemia para endurecer regimes, como Orban na Hungria e Añez na 
Bolívia. Houve os arrependidos que corrigiram rotas, como Boris Johnson, premiê do Reino Unido, e o governo sueco, após meses de negação. Houve as boas surpresas, como o controle sanitário na África. Houve as cenas indizíveis, como as de corpos jogados pelas ruas de Guayaquil, no Equador. Houve debate mundial sobre o papel da OMS, rompimento dos EUA com a organização, criação de um fundo internacional (Covax) para garantir vacinas para todos. Houve Jogos Olímpicos adiados, gigantes da aviação quebradas, médicos cubanos salvando vidas e EUA bloqueando a circulação de máscaras e insumos básicos. Houve o Brasil campeão mundial em mortes de profissionais de saúde e de grávidas infectadas. Houve os bons exemplos, como o do Vietnam, com pouquíssimos infectados e mortos. Houve reeleição garantida pela condução na pandemia, como a de Jacinda Ardern, premiê da Nova Zelândia. E o ano termina com pelo menos quatro vacinas promissoras já em fase de aplicação em vários países (menos Brasil).

\section{Olhos voltados para os EUA}

O ano pandêmico foi também de eleições nos EUA. Ainda em janeiro as atenções estavam voltadas para o processo de impeachment de Trump, do qual ele logo escapou. Na sequência viu-se uma corrida acirrada pelo posto de candidato democrata a enfrentar Trump nas urnas. Sanders se posicionou bem, mobilizou apoios e logo virou alvo dos democratas conservadores. Prevaleceu Joe Biden, ex-senador e ex-vice presidente de Obama, como candidato. Para concorrer ao cargo de vice-presidente foi escolhida a senadora da Califórnia Kamalla Harris. Frente à pandemia, Trump adotou a narrativa de que o país estava sendo atacado por um "vírus chinês". Ao mesmo tempo, garantia ser apenas uma gripe inofensiva. Foi desmascarado pelo livro de entrevistas (Fúria) do jornalista Bob Woodward, que retratou como Trump tinha consciência da gravidade do vírus. Ao contrário de Boris Johnson, do Reino Unido, ao contrair o vírus e ser internado Trump não mudou de postura. Tudo isso se deu em um ano marcado pelos gigantescos protestos antirracistas no país, surgidos em reação à morte de um homem negro, George Floyd, asfixiado por um policial branco. No último ano de Trump, foi assinado acordo com os Talibãs no Afeganistão, foi anunciado o "acordo do século" de anexação da Palestina por Israel, foi enterrado o NAFTA e firmado o T-MEC. O BID passou a ter o primeiro presidente indicado pelos EUA em toda a sua história. Cresceram os conflitos com China e Irã. Em novembro, Biden venceu as eleições presidenciais e Trump não reconheceu a derrota. Em processo de transição para assumir a Casa Branca, Biden se vê pressionado de todos os lados quanto à relação a ser estabelecida com o Irã. Por seu turno, Trump encomendou suas últimas maldades antes de deixar o cargo, entre elas mais restrições a Cuba e mudanças no mapa do Marrocos contra o povo do Saara Ocidental. 


\section{América Latina}

Em nossa região, destacam-se sobremaneira as vitórias populares na Bolívia e no Chile. Os bolivianos elegeram Luis Arce, do MAS, como presidente e receberam o ex-presidente Evo Morales de volta ao país. Após as eleições, a ex-presidente de fato, Jeanine Añez, e ex-ministros tentaram fugir da Bolívia (alguns conseguiram). No ano em que o Chile celebrou os 50 anos da vitória de Allende, a população aprovou em plebiscito popular enterrar a constituição pinochetista e realizar uma nova constituinte. $\mathrm{Na} \mathrm{Ar-}$ gentina, Alberto Fernández começou seu governo com o enorme desafio da pandemia, alcançou a reestruturação da dívida e teve pautas importantes aprovadas no parlamento. Ao final do ano foi aprovada a lei do aborto legal na Câmara (votação no Senado em 29 de dezembro). O país perdeu o ídolo Diego Maradona. No Uruguai, tomou posse o neoliberal Lacalle Pou, que logo retirou seu país da Unasul. Já Carolina Cosse, do partido Frente Amplio, venceu as eleições para o governo de Montevidéu. O país também perdeu o ex-presidente Tabaré Vázquez, falecido aos 80 anos. A Colômbia seguiu como preposto do Governo dos EUA na região, passou a ser membro pleno da OCDE e relembrou os quatro anos dos acordos de paz imersa em profunda violência. A Venezuela continuou pressionada pelo Grupo de Lima, agora enfraquecido, e conseguiu amenizar sua crise econômica com o auxílio do Irã, que enviou navios cargueiros com combustível e instalou supermercados no país. Em dezembro os venezuelanos elegeram uma nova Assembleia Nacional. Guaidó viu fracassar sua consulta popular e termina o ano perdendo apoio da União Europeia. No Peru, houve eleições legislativas no começo do ano, com o fujimorismo como grande derrotado, e uma espantosa troca de presidentes no segundo semestre. $O$ parlamento peruano cassou o mandato presidencial de Vizcarra e assumiu Merino, que também foi derrubado e substituído por Sagasti. Viram-se muitos protestos nas ruas. Na Guatemala também houve manifestações contra a lei do orçamento para o próximo ano; até um suspeito incêndio no Congresso ocorreu em meio aos protestos. No Equador, o candidato apoiado pelo ex-presidente Rafael Correa teve sua chapa homologada e está bem posicionado nas pesquisas para as eleições de fevereiro próximo. Cuba continua estrangulada pelo bloqueio econômico; ainda assim deu valiosas contribuições ao mundo durante a pandemia, não só com o desenvolvimento de fármacos e a vacina Soberana I, mas com a oferta de recursos humanos especializados. Reelegeu-se para o Conselho de Direitos Humanos da ONU e lidou com o movimento San Isidro, plantado para desestabilizar seu governo. Para 202I, o país anunciou a unificação de suas moedas.

\section{Política externa brasileira}

No Brasil, teve sequência uma política externa desastrosa. Ao longo do ano, seis ex-chanceleres brasileiros assinaram carta pela reconstrução da política exterior. Em 
termos de diplomacia presidencial, Bolsonaro visitou a Índia, foi aos EUA em março encontrar Trump e voltou com a comitiva infectada pelo coronavírus. Ao fim do ano, realizou a primeira reunião com o presidente argentino Alberto Fernández. Enviou Temer ao Líbano em agosto, após explosão do porto de Beirute, nomeou Nestor Foster embaixador nos EUA, fez uma fala repleta de fake news na Assembleia Geral da ONU, disse na reunião do Brics que o Brasil exporta madeira ilegal, ausentou-se das responsabilidades ambientais brasileiras na reunião do $\mathrm{G} 2 \mathrm{O}$, foi criticado na ONU pela péssima condução do país durante a pandemia e viu o Brasil ser excluído do encontro mundial realizado por ocasião dos cinco anos do Acordo de Paris. Permitiu que o Brasil fosse usado pelos EUA para ameaçar a Venezuela, com pressão sobre os diplomatas venezuelanos para deixarem o Brasil e permissão a Mike Pompeo para circular à vontade com seu intervencionismo em visita a Roraima. O Brasil também participou do lançamento, junto com EUA, Hungria e Polônia, da Aliança pela Liberdade Religiosa. Continuou sendo atacado externamente pela má gestão ambiental, com destaque, neste ano, para os incêndios no Pantanal, cujas imagens correram o mundo. Destaque também para os ataques desferidos à China e seus diplomatas, acusando o maior parceiro comercial do país de possível espionagem no caso da participação da Huawei na infraestrutura 5G. Em termos multilaterais, o Brasil assumiu a Presidência do Banco do BRICS e também a do Alto-Comissariado das Nações Unidas para os Refugiados. O chanceler Araújo admitiu para jovens diplomatas que o país é hoje um pária internacional.

\section{União Europeia}

Profundas divisões foram reveladas na União Europeia na condução da crise pandêmica. Por vários meses, os países do bloco não conseguiram chegar a um acordo sobre medidas a tomar contra a pandemia, econômicas sobretudo. Em julho, já sob a presidência da Alemanha, foi alcançada a aprovação de pacote econômico de reconstrução pós-pandemia. Países mais ricos do norte entraram em conflito com os mais pobres do sul quanto aos subsídios financeiros para salvamento da crise. O Brexit continuou como um tema forte e, enquanto estas notas são escritas, acaba de ser anunciada a chegada a um acordo comercial entre Reino Unido e UE poucos dias antes do prazo firmado (3I de dezembro). Nos dois países que configuram as maiores ameaças à democracia na região, Polônia e Hungria, no primeiro o ultraconservador Andrzej Duda foi reeleito e no segundo acaba de se formar uma promissora coalizão da oposição ao presidente Viktor Orbán. Rápidas sobre Europa: começou o julgamento de extradição de Julian Assange, que corre risco de morte na prisão inglesa; professor francês foi decapitado após mostrar charges com alusões a Maomé; cresceu debate sobre o radicalismo islâmico na França; maior campo de refugiados da Grécia foi incendiado. 


\section{China, Rússia e Ásia}

Foi aprovada na China uma nova Lei de Segurança Nacional para Hong Kong. A Rússia aprovou mudanças constitucionais via referendo popular. China e Rússia estreitaram seus laços de cooperação (vide declaração conjunta de II de setembro). China e Índia tiveram conflito armado no Himalaia. No Japão, o primeiro-ministro Shinzo Abe renunciou e assumiu seu colaborador mais direto. China concluiu debate sobre o I4 $4^{\circ}$ Plano Quinquenal (202I-2025) e anunciou erradicação da pobreza extrema no país às vésperas dos cem anos do Partido Comunista Chinês. Aumentou a tensão no mar do Sul da China, com reposicionamento de embarcações militares dos EUA. Houve conflito na fronteira entre as duas Coreias. Foi assinado o acordo comercial asiático RCEP, que terá grande impacto econômico no próximo período.

\section{Oriente Médio e Norte da África}

O ano começou com o assassinato do general iraniano Soleimani no Iraque e terminou com a execução de um físico nuclear do Ministério da Defesa do Irã, o que deixou quente a tensão do país com Israel e EUA. A guerra prolongada da Síria teve eventos importantes na região de Idlib. Israel terminou o ano convocando a quarta eleição em dois anos, após um 2020 em que Netanyahu precisou dividir o poder com Gantz. Trump e Netanyahu apresentaram o acordo "do século" para anexação da Palestina, e estabeleceram as relações diplomáticas de Israel com Emirados Árabes Unidos, Bahrein, Sudão e Marrocos. Além dos acordos secretos com a Arábia Saudita. Líbano viveu ano de protestos contra o governo e explosão catastrófica no porto de Beirute.

\section{África}

Em 2020 ano houve fortalecimento da União Africana, principalmente a partir de seus acordos com a China. Houve perdão de dívidas pelos chineses e construção de um grande Centro de Controle de Doenças em Adis Abeba, na Etiópia, para circulação de suprimentos e fármacos com maior agilidade. Houve golpe militar no Mali, na Guiné-Bissau e conflito armado na Etiópia (premiê é Nobel da Paz).

\section{Economia}

As bolsas de valores tiveram quedas drásticas com as notícias do coronavírus. Poucos países conseguiram escapar do desastre econômico da pandemia. Houve queda histórica nos preços dos barris de petróleo e crise na Opep. Cepal fez projeções terríveis e acertadas de queda ( $9 \%$ ) da economia na América Latina. PIB chinês foi recuperado 
(único país do mundo com curva econômica em "V" em 2020). OCDE, Banco Mundial e FMI terminaram o ano com projeções preocupantes para a economia mundial em 202I, especialmente para países como o Brasil.

\section{Conflitos quentes}

Guerra entre Armênia e Azerbaijão pelo controle da região de Nagorno-Karabakh. Invasão do território do Saara Ocidental pelo Marrocos com reação armada da Frente Polisário. Guerras na Síria, Líbia e Iêmen.

\section{Efemérides}

O aniversário do fim da Segunda Guerra Mundial em 1945 foi a grande efeméride do ano. Um desfile em Moscou marcou os 75 anos da vitória sobre os nazistas. A Assembleia Geral da ONU celebrou seus 75 anos de existência e a Europa lembrou os 75 anos da abertura dos portões de Auschwitz.

* Socióloga, doutora em Ciência Política (UFMG) e analista internacional. Leia as notas internacionais de Ana Prestes todas as semanas nos sítios 121, Ópera Mundi, revista Fórum, blog $O$ Cafezinho e portal Vermelho.

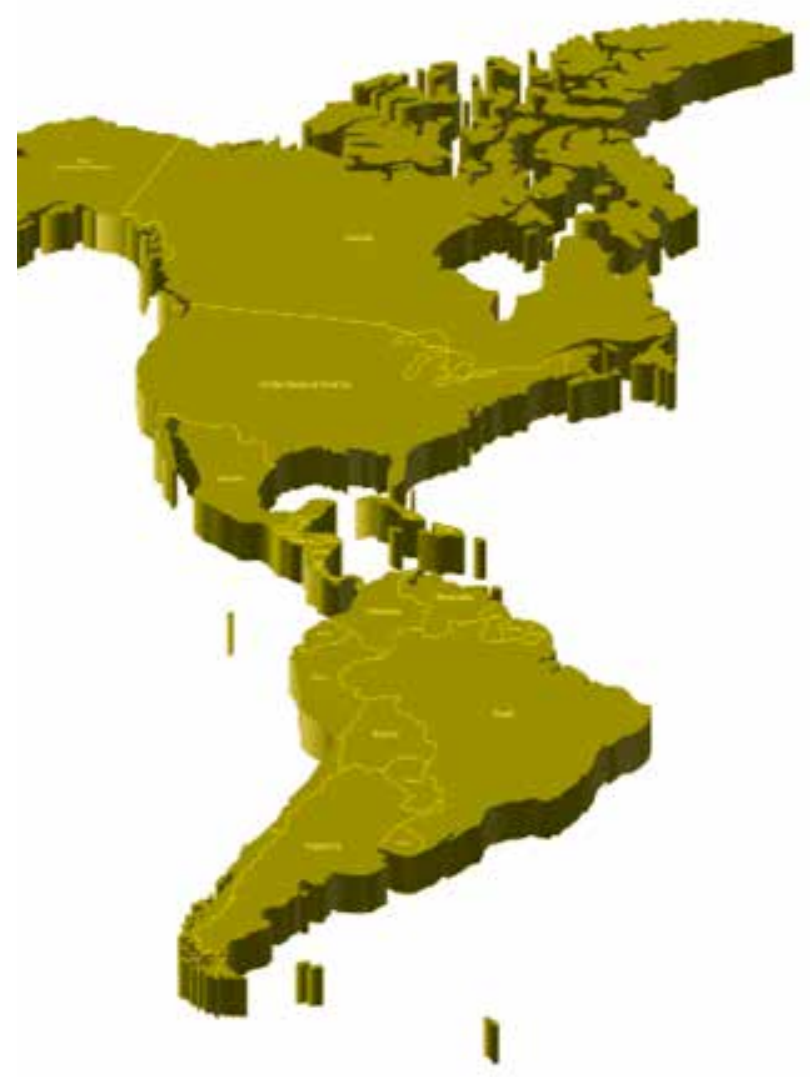

